Historic, Archive Document

Do not assume content reflects current scientific knowledge, policies, or practices. 



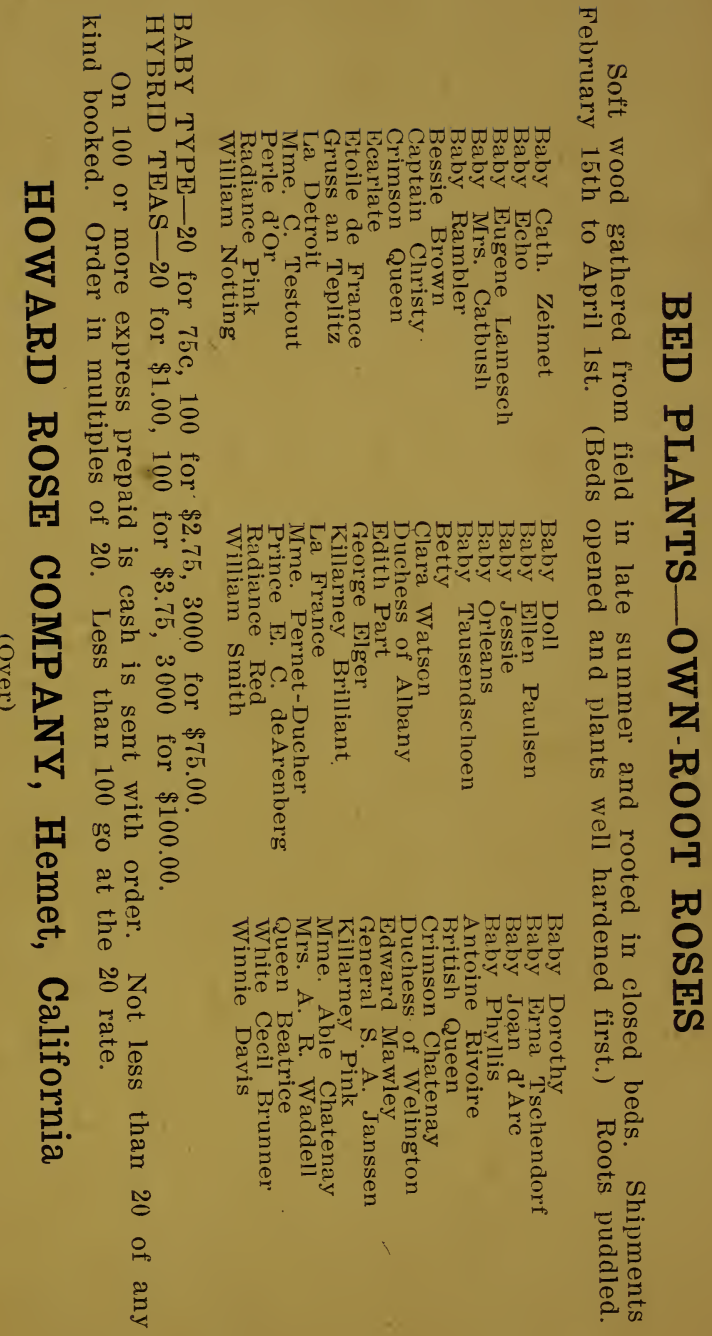




\section{A FEW GOOD THINGS}

Howard Rose Company,

Fort Worth, Texas, March 21, 1919.

Hemet, California

"Gentlemen:-The Roses we got from you were very satisfactory. They arrived in A-1 condition and grew very nice though we got ours late, etc. -

Yours very truly,

Wenatchee, Wash., March 27, 1919.

Howard Rose Company,

Hemet, California

"Gentlemen:-In answer to yours of the 22nd. We are pleased to state that the rooted Roses, from beds, reached us in good shape and were more than satisfactory to, us and this spring they are in fine shape, etc.-",

Howard Rose Company,

Stockton, Cal., March 27, 1919.

Hemet, California

"Gentlemen:-In reply to your favor of March 22 d would say that the rooted Roses from beds you sent us last year arrived in good condition and were very satisfactory. We are sorry that you did not have any to offer this year as we found it a very good investment, etc.-",

Yours truly,

Howard Rose Company,

Lubbock, Texas, March 27, 1919.

Hemet, California

"Gentlemen:-In reply to your request will say that the Rose cuttings reached us in fine condition and we were well pleased with the results even through the most extensive drouth I ever experienced.' We had good success and have lookfor your ad to come out this spring, etc.-" Yours truly,

Howard Rose Company,

Clayton, Mo., March 26, 1919.

Hemet, California

"Gentlemen:-We are in receipt of your favor of March 21st, and beg to assure you that the young Roses which we received from you last snring have been most satisfactory."

Yours very truly,

Howard Rose Company,

Ashley, Ill., March 31, 1919.

Hemet, California

"Dear Sir:-In reply to yours of the 22nd will say: The Roses were a good quality and when they arrived, the foliage had become so dry that most of it dropped off while planting them, but most of them lived and promise to yield us a nice crop of Roses this year, etc.-

Very truly, 